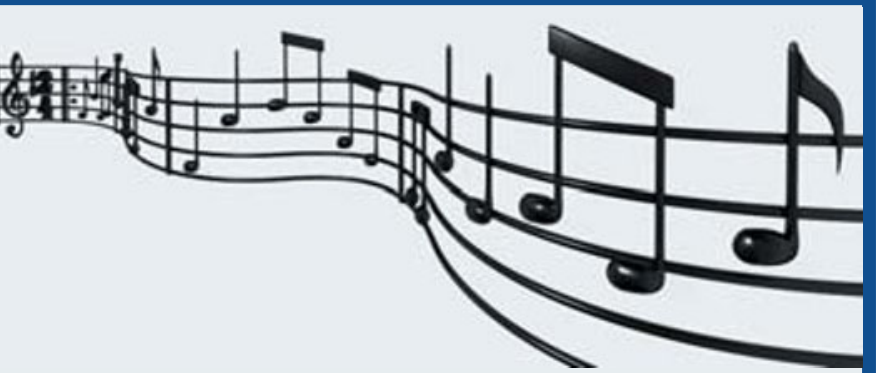

(Uro)-News, kommentiert von den BEATLES (3)

Dienstwagen-Gebrauch von (Ex-) IOWiG-Chef Sawicki umstritten: „Drive My Car“

Lauterbach plädiert für Abschaffung der $10 €-$ Kassengebühr: "I'll Be Back“

Kassen wollen die $10 €-G e b u ̈ h r$ beibehalten: "Think For Yourself"

Obama auf Mehrheiten für seine Gesundheitsreform angewiesen:

"With A Little Help From Your Friends“

Kassen wollen Zusatzbeiträge erheben: "What You Are Doing“"

Rösler holt GKV-Mann in sein Ministerium: "Two Of Us"

Ulla Schmid's „Das steht mir zu“ wird Satz des Jahres 2009:

"She Said She Said“

Rösler für kürzere Wartezimmerzeiten: "Wait"

Urteil des Sozialgerichts

\title{
Kryokonservierung von Spermien ist keine Kassenleistung
}

- Wer vor einer Hodenkrebsbehandlung vorsorglich Samenzellen einfrieren lassen will, muss damit rechnen, dies aus eigener Tasche finanzieren zu müssen, denn die gesetzliche Krankenkasse ist in diesem Fall nicht zur Kostenübernahme verpflichtet. So urteilte das Sozialgericht Aachen im Fall eines jungen Mannes, der vor Gericht die Kostenübernahme hatte durchsetzen wollen (S 13 KR 115/og), da das Bundesverwaltungs- gericht einem Beamten in Rheinland-Pfalz die Kostenübernahme zugestanden hatte.

Ausschlaggebend sei hier allein der Gemeinsame Bundesausschuss (G-BA), dessen Richtlinien die Kryokonservierung von Samenzellen nicht als Teil des Leistungskatalogs der gesetzlichen Kassen vorsehen. Dass manche Bundesländer im Beihilferecht für ihre Beamten anders verfahren, sei dabei nicht von Belang.

gri/dka
Humane Papillomviren

\section{Krebsgen schaltet angeborene Immunantwort aus}

- Das humane Papillomvirus Typ 16, der häufigste Erreger des Zervixkarzinoms, schaltet in seinen Wirtszellen ein wichtiges Signalmolekül der Immunabwehr aus. Fehlt die körpereigene Abwehr, können die Erreger die Schleimhautzellen umso erfolgreicher befallen. Für diesen Me-

\section{PSA-Screening: Jeder achte Wert falsch positiv}

- PSA-Messungen führen - selbst bei hoch angesetzten Grenzwerten - häufig zu falschem Alarm: Nach den Ergebnissen einer finnischen Studie ist jeder achte PSAWert falsch positiv [Brit J Cancer; Online-Vorabpublikation; doi: 10.1038/sj.bjc.6605512]. Für die betroffenen Männer war dies in zweifacher Hinsicht bedenklich: Zum einen, weil invasive Untersuchungen durchgeführt wurden, die gar nicht nötig waren. Zum andern sank ihre Bereitschaft, die Untersuchung nach vier Jahren zu wiederholen - selbst dann, wenn ein Erkrankungsrisiko bestand.

dka

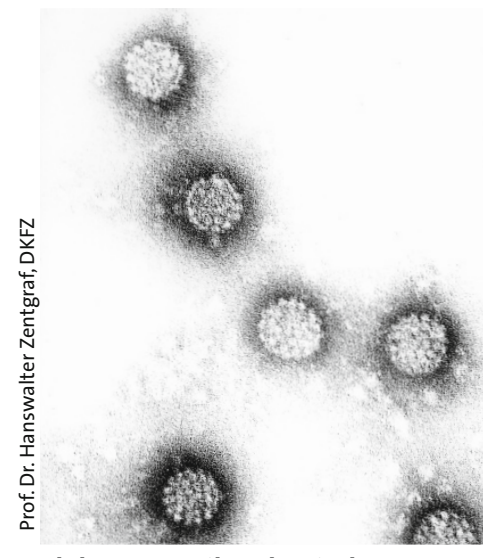

Elektronenmikroskopische Aufnahme von humanen Papillomviren. teine nicht mehr. chanismus ist das virale Protein E6 verantwortlich, wie Dr. Bladimiro Rincon-Orozco aus dem Team um Prof. Frank Rösl vom Deutschen Krebsforschungszentrum herausgefunden haben: Das Krebsgen schaltet die Produktion des Immunbotenstoffs Interferon-kappa durch biochemische Modifikation der DNA aus [Cancer Res 2009; 69: 8718-25]. Interferon-kappa ist für HPV-Infektionen von besonderer Bedeutung, da es vor allem in Keratinozyten produziert wird - also dort, wo sich die Viren bevorzugt einnisten. Fällt Interferon-kappa in den Zellen aus, funktionieren auch andere an der Immunabwehr beteiligte Pro-

Als Nächstes wollen die Forscher nun untersuchen, ob sich durch Gabe von Interferon-kappa das Wachstum von Gebärmutterhalskrebszellen bremsen lässt. Dies könnte eine künftige Grundlage für eine unterstützende Behandlung des Zervixkarzinoms darstellen.

dka 